\title{
Sero-bacteriological detection of bacteria in the gall bladder, blood and stool of patients having cholecystectomy
}

\author{
Ansaam M. Hamdoon, Zen Al-Abdeen Abdul-Allah \\ Department of microbiology College of Medicine University of Mosul
}

(Ann. Coll. Med. Mosul 2008; 34(2): 118-125).

Received:10 ${ }^{\text {th }}$ Apr 2008; Accepted: $2^{\text {nd }}$ July 2008.

\begin{abstract}
Objectives: 1- To identify the bacteria from the gall bladder and stool samples taken during cholecystectomy of patients with acute, and chronic cholecystitis of calculus and acalculus types. 2To use serological agglutination tests for the diagnosis of typhoid and brucellosis cholecystitis.3- To find out the antibiogram of the isolated bacteria from the different cases.
\end{abstract}

Methods: A prospective case series study was conducted at Al-Jumhori Teaching Hospital, and Ninevah and Al-Zahrawi Private Hospitals during the period from the $1^{\text {st }}$ of October 2003 to the $30^{\text {th }}$ of June 2004. A total of 150 patients undergoing cholecystectomy (134 females and 16 males)were studied. From each patient samples were collected from the gall bladder (bile, tissue biopsy and stone if present),blood for serological tests and stool (from 69/150 patients).

Results: Among the gall bladder samples, 101/150 (67.3\%) cases showed bacterial growth, the remaining 49 (32.7\%) cases had no growth. The bacterial growth was seen among $83.3 \%$ and $64.3 \%$ of acute and chronic cholecystitis respectively. A single agent per sample was detected in $62.4 \%$ of the cases, whereas mixed growth was identified in the remaining $37.6 \%$. The gram-negative bacteria were predominant and represented $86.7 \%$ of the isolates, while gram-positive ones were $13.3 \%$. The most common aerobic bacteria isolated were E. coli (19.3\%), while anaerobes were detected in only $5.3 \%$ of the isolates. The stool cultures showed similar microorganisms to those identified in the gall bladder samples in $74 \%$ of cases. In acute cholecyctitis all the gram-negative bacteria were sensitive to ciprofloxacin followed by ceftriaxone (96.5\%) and gentamycin (96.5\%). In chronic cholecystitis the most effective drug was ciprofloxacin (93.7\%) followed by amikacin (82.2\%). In both acute and chronic cholecystitis the least effective antibiotic was ampicillin.Typhoid cholecystitis was detected among four cases only, while brucellosis cholecystitis was not observed.

Conclusions: The bacteria causing acute and chronic types of cholecystitis are similar and predominantly are gram-negative bacilli. The intestinal origin of these microorganisms suggests ascending infection from the intestine to the biliary tract. Ciprofloxacin is the most effective drug against the isolated bacteria.

Keywords: cholecystitis, typhoid-cholecystitis, brucellosis-cholecystitis.

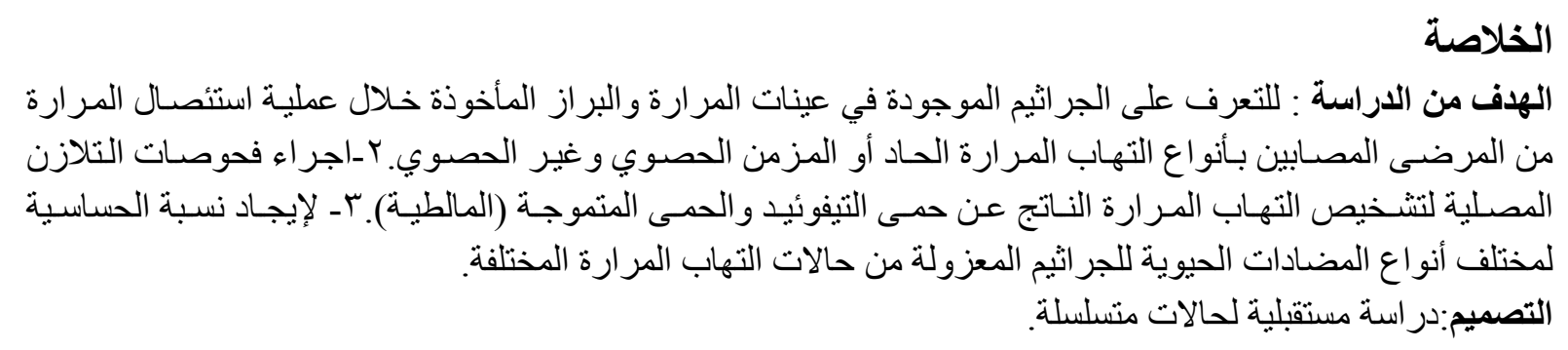


موقع الدراسـة: جمعت عينات هذه الدر اسـة من المستشفى الجمهوري التعليمي ومستشفى نينوى و الز هر اوي الأهليتـان

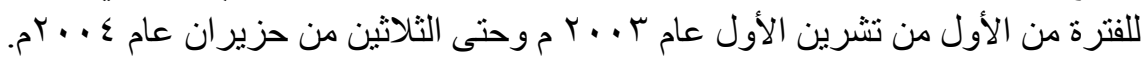

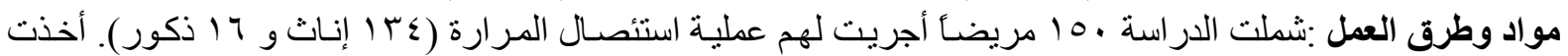

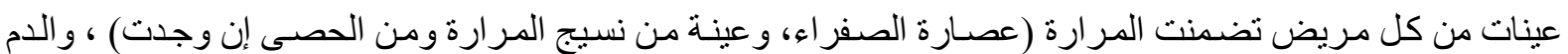

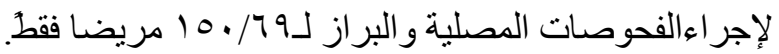

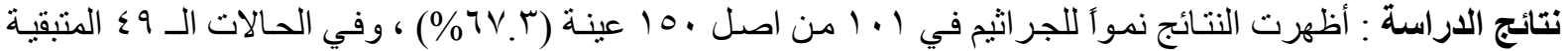

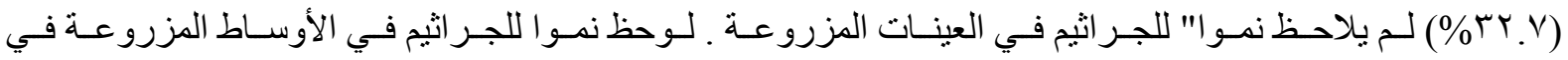

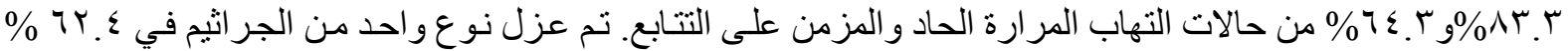

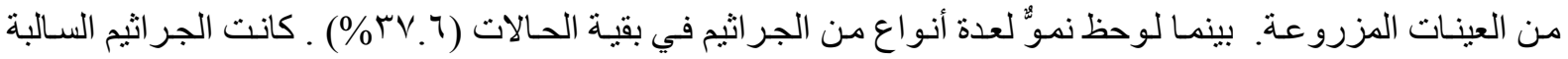

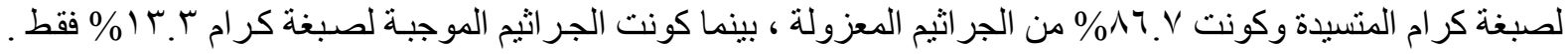

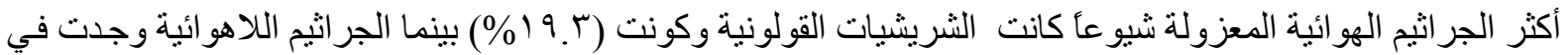

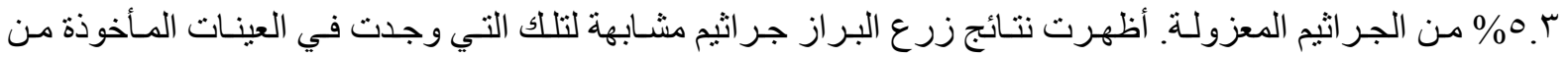

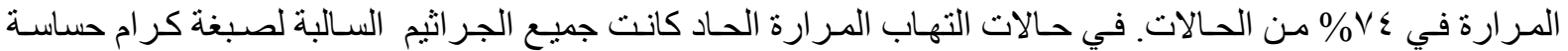

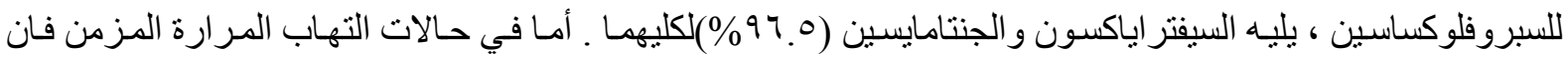

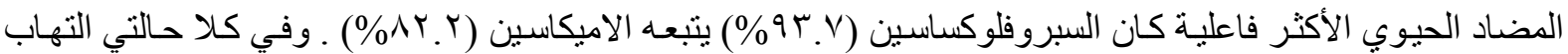

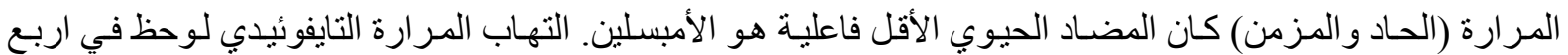

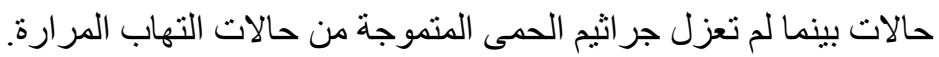

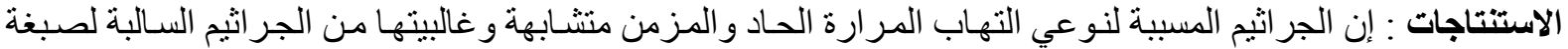

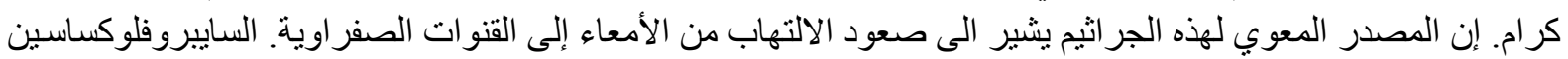

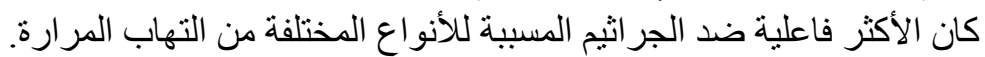

$\mathrm{C}$ holecystitis and cholelithiasis are fairly common diseases that are associated with serious complications. In $85-95 \%$ of the cases, inflammation of the gall bladder is associated with calculi $^{(1)}$. Acute cholecystitis is mostly associated with an obstruction of the neck of the gall bladder or cystic duct due to stone impacted in Hartmann's pouch. The disease is more common in females than males ${ }^{(1)}$. Enteric bacteria can be cultured from gall bladder bile in approximately half of patients with acute cholecystitis, but bacteria are not thought to contribute to the actual onset of acute cholecystitis. Emphysematous cholecystitis is a rare form of acute cholecystitis. It is usually of gangrenous type and caused by gas-forming microorganisms ${ }^{(2)}$.Emphysematous cholecystitis is characterized by the presence of gas in the gall bladder, and is more common in males than females ${ }^{(3)}$. The pathogenesis is related to acute inflammation of the gall bladder, which often begins aseptically and then complicated by a secondary infection with gas forming bacilli. These may reach the gall bladder by the bile ducts, blood stream or lymphatic channels and grow in an anaerobic environment.

Chronic cholecystitis is a chronic inflammation of the gall bladder and is generally associated with cholelithiasis with fibrosis of its wall. The bile is initially sterile, but may be secondarily infected with coliform bacilli, Streptococcus and occasionally Clostridia or Salmonella. Cholecystitis is the most common intraabdominal localized infection due to Salmonella ${ }^{(4)}$.

Acalculus cholecystitis is an acute or chronic inflammatory disease of the gall bladder, which can occur without stones. Acute acalculus cholecystitis is frequently a complication of sepsis, multiple organ failure or major operation. The incidence of chronic acalculus cholecystitis is less than $5 \%$, and the possible causes are thrombosis of major blood vessels, systemic disease as diabetes, specific infections as typhoid fever, actinomycosis and parasitic infestations ${ }^{(3)}$. 


\section{Materials and methods}

One hundred fifty patients undergoing cholecystectomy for acute or chronic cholecystitis, with or without cholelithiasis, were studied. The patients were 134 (89.3\%) females and $16(10.7 \%)$ males. They were of age 5-75 years.

Thirty cases of cholecystitis and 120 had cholecystectomy by open and laparoscopic surgery respectively. At operation, bile from the gall bladder, tissue biopsy from the wall and stone (if present) were taken for bacterial culture. All specimens were collected aseptically in sterile sealed containers, and were cultured within 1-2 hours after sampling. Stool samples or rectal swabs were also taken from 69/150 enrolled in the present study. The stool samples were cultured within few minutes to 1 hour of the time of sampling. About 3 milliliters of venous blood were taken from all patients in plain tubes and centrifuged for 10 minutes at 2500 RPM. The sera were separated and used for serological tests either immediately or kept frozen at $-20 C^{\circ}$ until use.

\section{Bacterial culture}

The bile and stool samples were processed for aerobic and anaerobic bacterial isolation. The samples were inoculated separately on MacConkey's (Difco,USA) and S-S (HiMedia,India) agars and incubated aerobically at $37 \mathrm{C}^{\circ}$ for 24 hours, extended to 48 hours incubation if there was no growth. The samples were also inoculated on duplicate of blood agar plates; one incubated anaerobically using Gas Pack Generating Kit (Oxoid,England) for 48 hours and the other plate incubated aerobically for 24 hours. The bile and the rectal swabs were also inoculated in tetrathionate broth at $37 C^{\circ}$ for 24 hours and then subcultured on MacConkey's and S-S agars. If bacterial growth was detected in any of the culture medium, the result was reported as positive. Pure culture was obtained from the positive media for further identification by standard biochemical tests and antibiotic sensitivity testing ${ }^{(5)}$.

\section{Serological tests}

The following serological tests were done on the serum samples:

a- Brucella agglutination test and 2Mercaptoethanol test (2-ME) for brucellosis using rose bengal reagent (Merck-U.K.) by rapid slide titration method ${ }^{(6)}$.

b- Widal test using stained febrile antigens (Pasmatec Laboratory products-UK) applying rapid slide agglutination according to the manufacturers and $2 \mathrm{ME}$ test ${ }^{(7)}$.

Results of the tested microorganisms were compared with those of the control group and then reported. The isolates were tested against different antibiotics according to their Gram staining results. The Gram-negative bacteria were tested against ciprofloxacin, amikacin, norfloxacin, ceftriaxone, gentamicin, chloramphenicol, ceftazidime, tetracycline, cephalexin, pipericillin, cotrimoxazole, cefotaxim, ampicillin and cefoxitin.

The Gram-positive bacteria were tested against chloramphenicol, ciprofloxacin, ampicillin, ceftriaxone, amikacin, cephalexin, gentamycin cotrimoxazole, tetracycline, erythromycin, vancomycin, clindamycin, norfloxacin, pipericillin and cefoxitin.

\section{Results:}

The 150 patients studied were subdivided into two groups. The first one included 126 (84\%) patients with chronic cholecystitis and the second group involved 24 (16\%) patients with acute cholecystitis.

The presence of cholelithiasis was investigated by ultrasonography prior to the operation as well as by direct identification during surgery. One hundred twenty $(80 \%)$ of the first group had gall bladder stones (calculus) and 6 (4\%) were acalculus. Eighteen (12\%) of the second group were calculus and 6 (4\%) were acalculus.

The patients were subdivided according to their ages into seven groups (Table 1). The ages ranged between 5-75 years (mean \pm $S D=39.9 \pm 13.2$ ), with a peak at the age of 35-45 years (in about $1 / 3$ cases). The males were 16 cases $(10.7 \%)$ whose ages ranged between 5 60 years (mean $\pm S D=35.75 \pm 16.2$ ). The females were 134 cases (89.3\%) with ages ranged between 8-75 years (mean \pm SD $=40.4$ \pm 12.7 ). Positive cultures of the gall bladder samples were most commonly seen in the age groups of 25-34 years, followed by the ages of $>65$ years ( Table 1 ). 
The overall cultures of the gall bladder samples showed bacterial growth in 101/150 (67.3\%) cases and the remaining 49 (32.7\%) cases had no growth. The total number of isolates was 150 microorganisms. The gramnegative isolates were 130/150 (86.7\%) microorganisms, while the gram positive ones were 20/150 (13.3\%) (Figures 1and 2). In acute cholecystitis, culture positivity was seen in $20 / 24(83.3 \%)$ cases, while in chronic cholecystitis it was detected in 81/126 (64.3\%) patients.

A single agent per sample was detected in $65(62.4 \%)$ cases, while mixed growth (2-5 different microorganisms) was identified in 36 (37.6\%) cases.

Aerobic bacteria were detected in 94 (93.1\%) cases, while mixed aerobes and anaerobes were identified only in $7(6.9 \%)$ cases (Table 2). No anaerobic microorganism was identified alone. These anaerobic microorganisms were 6 (4\%) Bacteroides fragilis and 2 (1.3\%) Clostridium perfringens. The stool culture showed microorganisms similar to those identified in the gall bladder samples in $74 \%$ of cases. Culturing all samples collected via open and laparoscopic approaches showed similarity in the types of microorganisms isolated.
The antibiograms of the bacteria isolated from the gall bladder samples of acute and chronic cholecystitis were determined. The gramnegative isolates from these two conditions showed more comparable antimicrobial sensitivity pattern ( $<5 \%$ difference) than the gram positive bacteria for most (12/14) of the antimicrobial agents used.

Brucella agglutination test was positive only among 9/150 cases of cholecystitis studied. All positive cases were of chronic calculus cholecystitis type. None of these cases showed the Brucella microorganism in cultures of their gall bladder samples.

Widal agglutination test was positive among $31 / 150$ cases studied. The majority (25/31) of the Widal positive cases belong to chronic calculus cholecystitis. Moreover, the 2MEWidal agglutination test was only positive among 4/31 cases. Three out of the four cases were chronic calculus cholecystitis type. All the four 2ME-Widal positive cases showed growth of microorganisms causing enteric fever in their gall bladder samples. Three of them were Salmonella typhi and only one was Salmonella paratyphi-A.

Table 1 :The distribution of culture positive and stone formation according to the age group of patients.

\begin{tabular}{|c|c|c|c|}
\hline \multirow{2}{*}{ Age range } & \multicolumn{3}{|c|}{ No. (\%) } \\
\cline { 2 - 4 } & Cases & Positive culture & Calculus cases \\
\hline \hline $5-14$ & $3(2)$ & $2(66.7)$ & $1(33.3)$ \\
\hline $15-24$ & $14(9.3)$ & $11(78.6)$ & $14(100)$ \\
\hline $25-34$ & $29(19.3)$ & $18(62.07)$ & $26(89.7)$ \\
\hline $35-44$ & $51(34)$ & $36(70.6)$ & $46(90.2)$ \\
\hline $45-54$ & $27(18)$ & $21(77.8)$ & $26(96.3)$ \\
\hline $55-64$ & $21(14)$ & $9(42.9)$ & $20(95.2)$ \\
\hline $65-75$ & $5(3.3)$ & $4(80)$ & $5(100)$ \\
\hline Total & 150 & 101 & 138 \\
\hline
\end{tabular}

Table 2: The types of bacteria in culture positive cases.

\begin{tabular}{|c|c|c|c||}
\hline Types of isolates & No. (\%) of patients & $\begin{array}{c}\text { No. (\%) of bacterial } \\
\text { isolates }\end{array}$ & Range of isolates \\
\hline \hline Aerobes only & $94(93,1)$ & $142(94,7)$ & $1-4$ \\
\hline $\begin{array}{c}\text { Mixed aerobes and } \\
\text { anaerobes }\end{array}$ & $7(6,9)$ & $8(5,3)$ & $2-5$ \\
\hline \begin{tabular}{c} 
Anaerobes only \\
\hline
\end{tabular} & 0 & --- & -- \\
\hline
\end{tabular}




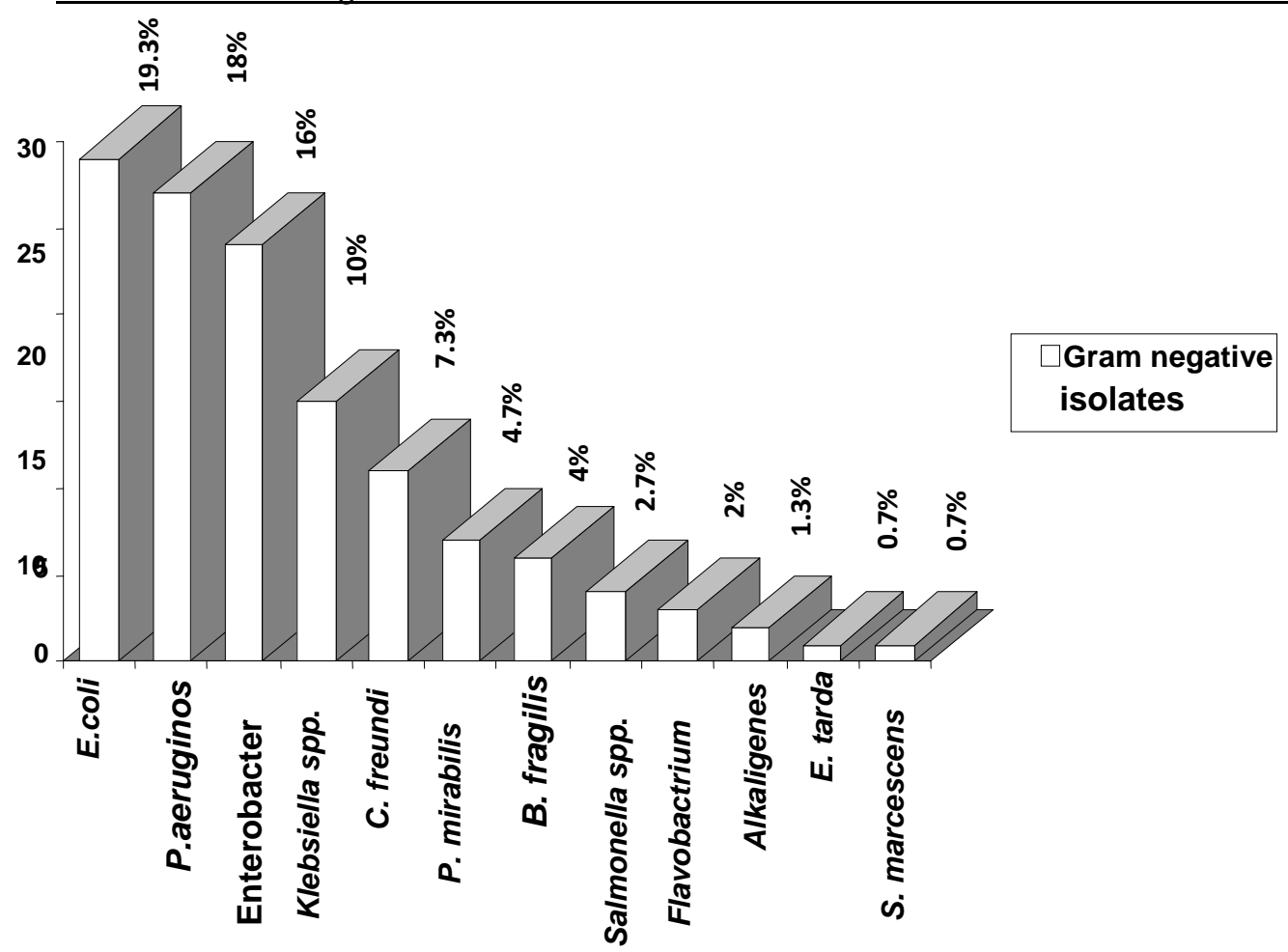

Figure(1): The frequency of the gram-negative bacteria in cholecystitis

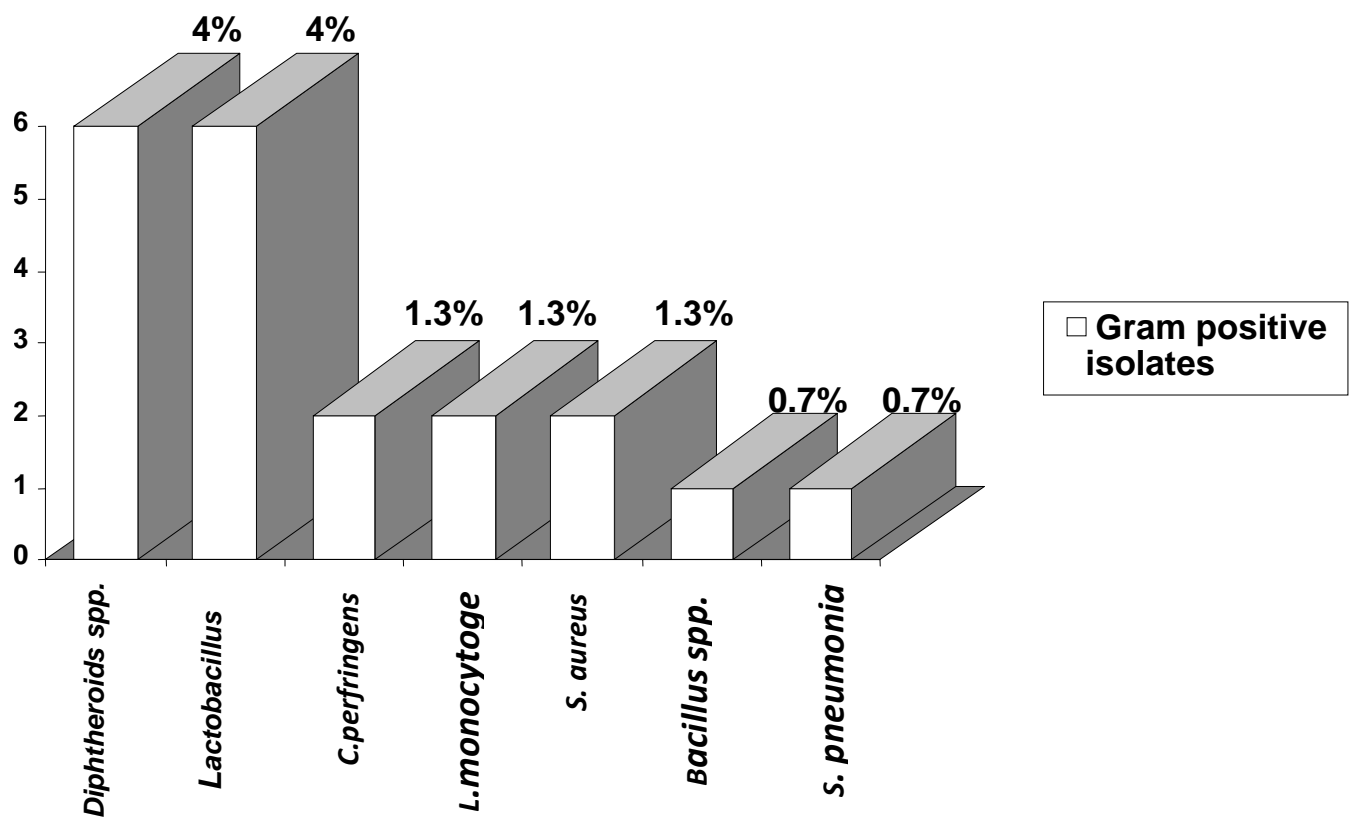

Figure(2): The frequency of the gram-positive bacteria in cholecystitis

\section{Discussion:}

Since the bile of normal subjects is sterile, the bacterial infection seems to play a role in the development of the gall bladder disorders $^{(8)}$.
Out of the 150 cases studied, 101 (67.3\%) cases yielded growth of many bacteria from the cultures of the gall bladder samples. Also, other studies had shown bacterial 
growth in cholecystitis in 55\%-70.4\% of their cases $^{(9-11)}$.

The biliary infection plays a role in brown pigment stone formation ${ }^{(12)}$. In the current study, the incidence of calculus cholecystitis was $92 \%$, while that of acalculus cases was $8 \%$. Other studies had also reported incidence of $90 \%$ for calculus cholecystitis and $10 \%$ for acalculus cholecystitis ${ }^{(2,4)}$.

In cases with calculus cholecystitis the incidence of positive cultural growth in gall bladder samples was $66.7 \%$. This result is in keeping with the findings of other studies that reported incidence of $64 \%-81 \%{ }^{(12-15)}$. However, other studies demonstrated lower incidence of $25 \%-42 \%{ }^{(16-19)}$. This difference could be due to the use of antimicrobial agents by the patient.

Also, the incidence of positive cultural growth of gall bladder samples in chronic (calculus and acalculus) cholecystitis was $65.45 \%$, while in another work it was $82 \%{ }^{(20)}$. Therefore, the incidence of bacteria isolated from cases with acute cholecystitis were more than those from the chronic cases, which may be attributed to the use of antibiotics by the patients.

The infection in cholecystitis can be caused by various types of bacteria either in single or mixed forms. The single agent per sample was detected in $62.4 \%$ of cases.However other studies reported slightly higher (70\%-75.8\%) recovery rates of single bacterial agent ${ }^{(10,15,21)}$. In the present study, various gram-negative and gram-positive aerobic and anaerobic bacteria were detected. The gram-negative bacteria constituted $86.7 \%$ of the isolates from the gall bladder samples, while grampositive bacteria were seen only among $13.3 \%$ of the isolates. Other studies reported isolation of gram-negative microorganisms in $27.1 \%-62 \%$ of the isolates and the grampositive bacteria in $27 \%-72.9 \%$ of the cultural growths ${ }^{(20,22,23)}$. The predominance of gram-negative bacteria may be attributed to the enteric origin of these microorganisms from the intestine which migrate to the biliary tract, particularly when there is partial obstruction by stone ${ }^{(8)}$. Consequently, the biliary stasis encourages bacterial growth and causes the primary tissue damage and inflammation. The ascending infection is probably the main portal of entry of enteric bacteria to the gall bladder. This is supported by the finding that the stool cultures showed growth of microorganisms similar to those isolated in the bile cultures of the same patients in $74 \%$ of cases. The bacterial species found in the bile of patients with biliary diseases both calculus and acalculus indicates that the intestinal flora is the main source of the bactibilia ${ }^{(23)}$.

In this study, the most common microorganism detected in cholecystitis was E.coli (19.3\%). Also, many other studies from different parts of the world had reported E. coli as the predominent (15.5\%-28.2\%) isolate from cholecystitis ${ }^{(11,15,16,19,20,24,25)}$. Pseudomonas aeruginosa was the second most common isolate (18\%) in cholecystitis. In other studies the incidence of this microorganism was slightly lower( 8.3\%$12.5 \%)^{(16,19,25)}$.

Salmonella can infect the gall bladder and cause cholecystitis, which is the most common intra-abdominal localized infection ${ }^{4}$. The incidence of Salmonella cholecystitis among our cases was $2.7 \%$. However, variable results (2.8-21.7\%) from India were reported previously ${ }^{(9,17)}$. These discrepancies may be due to the variations in the endemicity of this microorganism at different geographical localities, or related to alterations in the local or systemic immunity of the patients. The enteric fevers are rare causes of acute cholecystitis, but chronic typhoid cholecystitis is a more common condition. In these conditions, the patients pass the Salmonellae in the feces, which are derived from the focus of infection in the gall bladder. The gallstones may be a contributory factor for the occurrence of infection. Salmonellae were isolated from the biliary samples and the stool of only four $(2.7 \%)$ calculus cholecystitis cases (one acute and three chronic). These patients were biliary carriers of Salmonellae, which might have caused the cholecystitis. The diagnosis of typhoid cholecystitis of these 
cases was also confirmed (besides the culture) by positive Widal and Widal-2ME tests.

The culture of the gall bladder wall and bile gave almost identical results, except in some cases (10/77) of chronic calculus cholecystitis and one case of acute calculus cholecystitis in which the bacteria were found more often in the gall bladder wall than in the bile. This may be due to sessile bacterial population associated with the mucosa. Some studies reported variations between the rates of bacteria detected in the bile $(8 \%)$ from those isolated from the gall bladder wall $(23 \%)$ specimens ${ }^{(12)}$.

According to the antibiogram detected, it was evident that ciprofloxacin constituted the first-choice drug for the treatment of biliary tract infection caused by gram negative and gram-positive bacteria. This result is in agreement with other studies ${ }^{(11,26,27)}$. The use of quinolones is recommended because these agents can effectively penetrate the obstructed biliary tree.

The bacterial sensitivity to most antimicrobial agents in acute cholecystitis was higher than that in chronic cholecystitis among the majority of cases. This may be attributed to the repeated uses of antibiotics in chronic cholecystitis which lead to the development of resistant microorganisms.

\section{Acknowledgments}

We would like to express our thanks to Prof. Mozahim Al-khayatt, FRCS, Chairman of the Laparoscopic Surgery Unit at Aljumhori Teaching Hospital and its staff. Also, we appretiate the cooperation of both Ninevah and Al-zahrawi Private Hospitals in conducting the present study.

\section{References}

1. Bhansali SK .Cholelithiasis and cholecystitis. J.P.G.M. 1980;26 (1): 74-85.

2. Frederick JS. Biliary tract. In: Mark F, Bruce FS, Marrin HS $\left(6^{\text {th }}\right.$ ed) Sleissenger and Fordtron's gastrointestinal and liver diseases. W.B. Saunders Company. Philadelphia, Pennsylvania,USA 1997; p1606.
3. Seymour I and Schwarz S. gall bladder and extrahepatic biliary system. In: Schwartz SI, Shires GT and Spencer FC. Principles of surgery $\left(5^{\text {th }}\right.$ ed). McGraw-Hill Book Co.Singapore 1989; P1395.

4. 4Gerald TK. Salmonellosis. In: Eugene B, Anthony SF, Dennis LK et al., Harison's Priciples of Internal Medicine. (15 $\left.{ }^{\text {th }} \mathrm{ed}\right)$ McGraw-Hill Medical Publishing DivisionUSA 1998; p950.

5. JG Collee, AG Fraser, BP Marmion and et al, Tests for identification of bacteria.In: Mackie and McCartney, Practical Medical Microbiology $\left(14^{\text {th }}\right.$ ed) Churchill Livingstone; P131-51.

6. Dabdoob,W.A. and Abdullaziz,Z. A panel of eight tests in the serodiagnosis and immunological evaluation of acute Brucellosis. East Medit. J.2000;6:303-12.

7. Abdulla, Z.A.and Abdullah, E.T.Comparison of the Widal test and modified 2mercaptoethanol Widal test for the diagnosis of enteric fevers.J.B.M.J. 2007;19:33-37.

8. Herschel AC. Bacterial and parasitic cholangitis. Mayo Clin. Proc. 1998; 73: 473478.

9. Ballal $\mathrm{M}$, Jothi $\mathrm{KN}$, Antony $\mathrm{B}$ et al., Bacteriological spectrum of cholecystitis and its antibiogram. I.J.M.M. 2001; 19(4).

10.Kiesslich R, Holfelder M, Will D et al., Interventional ERCP in patients with cholestasis degree of biliary bacterial colonization and antibiotic resistance. $\mathrm{Z}$. Gastroenterol. 2001; 39(12): 985-992.

11.Rerknimitr R, Fogel E, Kalayci C et al., Microbiology of bile in patients with cholangitis with or with out plastic biliary endoprosthesis. Gastrointest. Endosc. 2002; 56(6): 885-889.

12. Alexander $\mathrm{S}$ and Sum PL. The role of bacteria in gallstone pathogenesis. Frontiers in Bioscience 2001; 6:93-103.

13. Bjornson ES, Kilander AF and Olsson RG () Bile duct bacterial isolates in primary sclerosing cholangitis and certain other forms of cholestasis. Hepatogastroenterology 2000; 47(36): 1504-1508. 
14.Lygia S, Oesterle LA, Ihsan E et al., Western pigment gallstones pathogenesis. Gastroenterol. J. 2001; 120(5).(Abstract)

15.Ansorg R, Folsch UR, Kieslich $\mathrm{N}$ et al., Microbiologic studies before and after endoscopic papillotomy. Infect. J. 1983; 11(5): 260-263.

16.Darko $\mathrm{R}$ and Archampong $\mathrm{EQ}$ The microflora of bile in Ghanians. West Afr. J. Med. 1994; 13(2): 113-115.

17. Sreekar B. A one-year cross sectional study of the bacteriological assay of gall stones. Nehro Medical College 2001. (Abstract).

18. Hadi AA () Qualitative analysis of gallstones. Al-Anbar Medical J. 2002; 4(1): 45-48.

19.Al-Harbi M, Osoba AO, Mowallad A et al., Tract microflora in Saudi patients with cholelithiasis. Trop. Med. International Health. 2001; 6(7): 570-574.

20.Claesson BE, Holmlund DE and Matzsch T Microflora of the gall bladder related to the duration of acute cholecystitis. Surg. Gynecol. Obstet. 1986; 162(6): 531-535.

21. Sheila $S$ and James D. Diseases of the liver and biliary system $\left(10^{\text {th }} \mathrm{ed}\right)$. Blackwell Science Ltd,Oxford, London 1997; p597.

22. Ujvary G, Kuttel P and Lazaritis J. Antibiotic management of bacterial bile duct and gall bladder infections. Acta. Chir. Scand. 1975; 16(2): 165-174.

23. Veselov A, Vitebskii I and Chernov V. Microflora of the gall bladder in chronic calculus cholecystitis and its antibiotic sensitivity. Antibiotiki. 1984; 29(1): 52-56.

24. Flores C, Maguilnik I, Hadlick E et al., Microbiology for choledocal bile in patints with choledocholithiasis admitted to a tertiary hospital. J. Gastroenterol. Hepatol. 2003; 18(3): 333-336.

25.22-Wayne PH and Whelan JG. Susceptibility testing of biliary bacteria obtained before bile manipulation. A. J. Roentgenol. 1983; 140(6): 1185-1188.

26. Claeson BE, Hollund DE and Matzsch T. Microflora of the gall bladder related to the duration of acute cholecystitis. Surg. Gynecol. Obstet. 1986; 162(6):531-5.

27. Ohdan $\mathrm{H}$, Oshiro $\mathrm{H}$, Yamamoto $\mathrm{Y}$ et al., Bacteriological investigation of bile in patient with cholelithiasis. Surg. Today 1993; 23(5): 390-395. 